\title{
SOBRE ÁNGEL GUERRA: ENTRE LA REVOLUCIÓN Y LA SANTIDAD
}

\author{
Marfa Luisa BURGUERA NADAL \\ Profesora-Tutora de la UNED, Valencia
}

\section{El Trayecto Hacia la OPCión Espiritualista}

Cuando Clarín en «La novela novelesca» se preguntaba sobre la posibilidad de que la literatura reflejase una cierta tendencia armónica, evidente manifestación de la transformación del positivismo, un afán generoso de paz e inteligencia que conllevaba el nuevo idealismo, el cual no negaba cosa alguna de lo contrario, estaba sentando las bases de esa nueva novela que buscaba «idealidad o poesía». El naturalismo debía dejar espacio para la novela psicológica. Y en boca del mismo Clarín: «Es particularmente legítima la forma de la novela que atiende al alma no por el análisis, sino por su hermosura, por la belleza de las expresiones nobles'."

Aún faltaban unos años para la publicación del prólogo a Resurrección de León Tolstoi; en él ya se manifestaban síntomas de un mayor dominio ide-

1 Lo recoge SERGIO BESER, en Leopoldo Alas: Teoría y crítica de la novela española, Barcelona, Laia, 1972, pág. 167; remite a «La novela novelesca», Ensayos y Revistas, Madrid, Fernández y Lasanta, 1892. 
ológico en la concepción del espiritualismo ${ }^{2}$. Pero nos ceñiremos al aspecto que nos interesa resaltar; Clarín, seducido por el atractivo de la novela tolstoiana y aún por la galdosiana, obsesionado en cierto modo por la moral redentorista, se pregunta sobre los modos de actuar en la vida de aquellos de «buena fe», «los que por real amor a la humanidad aspiran a cambiar la vida pública, corrigiendo sus defectos, buscando en nuevos procedimientos e ideales, el progreso de la sociedad ${ }^{3}$ »; éstos, a su entender, pueden seguir dos caminos: la dedicación directa a la reforma social, sin examinarse a sí mismos, o la previa «reforma interior» y el dominio de las propias pasiones para poder servir a los demás.

El primer camino lo siguen la mayoría de los reformadores; el segundo es el camino que siguió Cristo; así pues, y según Clarín, la diferencia que se ha dado entre el santo reformista social y el revolucionario es que éste último atendió exclusivamente a la perfección de la sociedad en tanto que el primero cuidó su propia conducta, su vida interior.

En esa opción de Revolución o Santidad encontramos a Ángel Guerra de Benito Pérez Galdós publicada en su primera edición en $1892^{4}$.

Nos proponemos esbozar el análisis de la transformación del personaje protagonista, Ángel Guerra puesto que creemos que es elemento esencial en la delimitación de la semántica global que define el texto o macroestructura de la obra $^{5}$. Las fuentes de información de las que nos serviremos serán las explícitas

2 Ver Olez., J., en el Prólogo a Su único hijo de Clarín, Madrid, Cátedra, 1990, págs. 37-40. El autor explica las características de la etapa espiritualista de Clarín en varios apartados que se refieren a: 1) lo que asume como patrimonio, 2) los elementos que se pierden, 3) lo que se ha transformado, y 4) lo nuevo que incorpora en este período.

3 Prólogo de L. Alas Clarín a Resurrección de L. Tolstol, 2* ed., Barcelona Maucci, 1901, Tomo I, pág. XIV.

4 J. OLEZA incluye a Ángel Guerra dentro de la producción de Galdós, en el grupo de novelas que responden a la realidad interiorizada (1892-1897), en la etapa del naturalismo al espiritualismo; en La novela del siglo XIX, Barcelona, Laia, 1984, págs. 125 y ss.

5 VAN Disk ubica la coherencia del texto en la estructura profunda del mismo y la denomina macroestructura; ésta se identifica con la estructura abstracta subyacente o forma lógica de un texto; coincide así con Greimas cuando habla de estructura profunda lógico-semántica, aunque los planteamientos de los dos autores difieran notablemente. La macroestructura puede ser vista como la representación semántica global que define el significado de un texto como un todo único. Señala también VAN DıJK el término de coherencia pragmática o coherencia global que sería asignada por el lector, que pertenecería a la interpretación del texto y que estaría sujeta no sólo a la recuperación de la competencia textual del lector. VER DIJK, T. A. VAN, Texto y contexto, Madrid, Cátedra, 1980 y Greimas, A. J., Semántica estructural, Madrid, Gredos, 1973. 
(el personaje mismo o el narrador) y las implícitas (las acciones) en la sucesión de acontecimientos que aparecen en el texto ${ }^{6}$.

En cuanto al narrador como punto de vista del cual parte el texto narrativo, hemos observado la aparición de un narrador-transcriptor en una sola ocasión y como muestra de afán de objetividad y verosimilitud:

«Señalan las crónicas al llegar a este punto dos hechos de suma importancia. Primero ... Segundo ...» (Ángel Guerra, Madrid, Alianza, 1986, pág. 576).

El resto de la narración responde a un punto de vista omnisciente; así pues el autor habla impersonalmente en tercera persona si bien esa ausencia de intrusiones no implica en modo alguno que él mismo deje de intervenir dentro de ese marco de neutralidad ${ }^{7}$.

\section{La Transformación de ÁNGEl GUERRA}

\section{El ahondamiento interior o el primer camino de perfección}

Creemos que la transformación de Ángel Guerra se da en tres fases: en la primera el punto de partida es el desengaño; un desengaño que le ha llevado al

6 Según Mieke Bal en Teoría de la narrativa, Madrid, Cátedra, 1989, pág. 13, "un texto narrativo será aquel en que un agente relate una narración»; el autor diferencia entre historia o «fábula presentada en cierta manera»; fábula o «serie de acontecimientos lógica y cronológicamente relacionados que unos actores causan o experimentan"; acontecimiento o «transición de un estado a otrow y actores o «agentes» que lleven a cabo acciones". El personaje sería el actor provisto de los rasgos distintivos que en conjunto crean el efecto de un personaje; es una unidad semántica completa; págs. 87 y ss.

7 Para el concepto de omniscencia, ver Norman Friedman en «Point of view in fiction: the development of a critical concept», PMLA, March, 1955, págs. 1160-1184; propone varias posibilidades; entre ellas señala la «Neutral Omniscencia» y afirma: «the prevailing charasteristic of omniscencia, however, is that the author is always ready to intervene himself between the reader and the story, and that even when he does set a scene, he will render it as he sees is rather than as his people see it»; op. cit., pág. 1174. 
olvido de la religión: [«Yo no rezo. Se me han olvidado las oraciones» (Ángel Guerra, op. cit., pág. 30)]; y que le conduce ahora a una clara conciencia del fanatismo anterior:

« ¿Desengaño como éste!. Paréceme que despierto de un sueño de presunción, credulidad y tontería y que me reconozco haber sido en este sueño persona distinta de lo que soy ahora ... En fin el error duele pero instruye. Treinta años tengo, querida mía. En la edad peligrosa cogiome un vếrtigo político, enfermedad del fanatismo, ansia instintiva de mejorar la suerte de los pueblos, de aminorar el mal humano, resabio quijotesco que todos llevamos en la masa de la sangre. El fin es noble; los medios ahora veo que son menguadísimos $y$ en cuanto al instrumento, que es el pueblo mismo, se quiebra en nuestra manos como una caña podrida...» (Ángel Guerra, op. cit., pág. 17);

y a una admiración por la fe de Leré y por lo espiritual frente a lo material:

«No creas que me disgusta notar en ti esa firmeza de convicciones, esa fe ardiente, ciega, como debe ser la fe, y capaz de llevarse tras sí las montañas. Yo no creo lo que tú crees; pero me da por admirar a los que creen así, con toda su alma, sin hacer de la fe una máscara para engañar al mundo ... Las personas que hacen gala de proscribir todo lo espiritual me son odiosas. Los que no ven en las luchas de la vida más que el triste pedazo de pan y los modos de conseguirlo me parecen muertos que comen. Lo mejor sería que hubiera en cada persona una medida o dosificación perfecta de lo material y lo espiritual; pero como esa ponderación no existe ni puede existir, prefiero los desequilibrados como tú, que son la idea neta, el sentimiento puro. Porque no hay que darle vueltas, querida Leré: una idea, la idea tiene más poder que todo el pan que puede fabricarse con todo el trigo que hay en el mundo» (Ángel Guerra, op. cit., pág. 119).

Es también ilustrativo el texto de OsCar TACCA, Las voces de la novela, Madrid, Gredos, 1985. El autor señala que la relación entre el conocimiento del narrador y el de sus personajes puede ser de tres tipos: omniscente, equiscente y deficiente (pág. 71 y ss.). Si el realismo es considerado como una visión objetiva del mundo, la novela en tercera persona de autor omniscente es la que más se le acerca; pero si el realismo es considerado como una imagen fiel no sólo del mundo sino del modo de captación de éste, la novela pretendidamente realista es la menos realista de todas. A este propósito habría que recordar la apreciación de MaUPASSANT en el prólogo a Pierre et Jean (1887) ya que diferencia entre realidad externa y visión que el espectador y el artista poseen de realidad. 
Inevitablemente nos remite ello al desengaño del propio Galdós tras la Revolución del 68 y la República y su anterior actitud revolucionaria; tal vez sería el momento de preguntarse sobre lo autobiográfico en la obra, pero ello nos conduciría a apreciaciones teóricas sobre el autor implícito no oportunas ${ }^{8}$.

No obstante la psicología de Guerra, según Clarín afirmaba, no se debe estudiar dentro de él sino en el mundo que le rodea ${ }^{9}$. Guerra llega pronto en el texto a una conciencia de inicio de cambio que se manifestará en una necesidad de comunicación, una justificación en la que explica los motivos que le han llevado a la revolución y que culmina con la confesión de un asesinato. Se hace presente sin duda el miedo de Galdós hacia el anarquismo individualista cuando descubre al individuo en rebeldía contra la sociedad ${ }^{10}$. Sin embargo también en la obra aparece cierta justificación de esa actitud revolucionaria:

«Hace tiempo que siento vivos deseos, ¿qué digo deseos?, necesidad de comunicarme con alguien, de aligerar y refrescar mi conciencia dando cuenta clara de los móviles de mis acciones, refiriendo lo que pueda disculparme, lo que no tiene disculpa, y, en fin, todo lo que he sentido porque de lo que se siente, Leré, nacen las acciones, y aquellas que parecen más disparatadas resultan no serlo tanto cuando se examina el corazón, que es la fuente, hija, la fuente de donde nace la voluntad. Desde que murió mi madre, vengo notando que se resquebraja dentro de mi todo el ser antiguo de mi vida y aquello que me parecía la misma consistencia amenaza desplomarse.» (Ángel Guerra, op. cit., pág. 140).

Por otra parte, Ángel Guerra, al igual que Galdós, presenció días después de la suolevación de los sargentos del cuartel de San Gil, el paso de los mismos

${ }^{8}$ En relación con el tema G. PORTNOFf afirma que la producción de Don BENito apenas es autobiográfica si la comparamos con la de TOLSTOl, quien se retrata en sus personajes; ver GEORGE PORTNOFF, La literatura rusa en España, Instituto de las Españas, New York, 1932, pág. 201. Sobre la actitud revolucionaria de GALDós y su posterior evolución, ver J. CASALDUERO, Vida y obra de Galdós (1843-1920), Madrid, Gredos, 1961, págs. 22-29.

9 Asi lo afirma Clarín en Galdós, 1912, pág. 244; MONROE Z. HAFTER en «Bálsamo contra bálsamo» Anales galdosianos, Año IV, 1969, pág. 39, afirma «The development of Angel's character seems always unfold in response to external stimulation»; remite a los estudios de S. H. EofF, The novels of Pérez Galdós, St. Louis, 1954; FRANCISCO RuIz RAMÓn, Tres personajes galdosianos. Madrid, 1964; AMADO ALONSO «Lo español y lo universal en la obra de Galdós», Materia y forma en poesia, Madrid, 1955.

10 Ver OlezA, J., La novela del siglo XIX, op. cit., pág. 112; parece ser que en su camino hacia la interiorización Galdós tuvo miedo de llegar a las últimas consecuencias. 
por la calle de Alcalá al sitio donde fueron fusilados. Este hecho, que quedó grabado en la mente del autor para siempre, se reflejó no solo en Ángel Guerra, donde aparece como un hecho que pretende justificar su modo de actuación, sino también en La de los tristes destinos.

Pero el revolucionario Ángel Guerra no era ni un héroe ni un sanguinario; probablemente se acercase más a la definición que Tolstoi da en Resurrección de los revolucionarios: seres cuyas necesidades morales estaban por encima de los demás; no eran héroes pero tampoco hombres llenos de ferocidad y poseían variados motivos para ejercer como revolucionarios ${ }^{11}$.

Algunos críticos han comparado a Ángel Guerra con Fortunata y de esta comparación resulta que si Fortunata es una marginada que busca integrarse en la sociedad burguesa, Ángel es un burgués que rechaza su clase, primero, mediante la revolución violenta, luego mediante el mesianismo; así la separación de la familia en Guerra poseería un carácter psicológicos más que histórico: cuando deja el hogar se separa de su familia y de su clase pero esto no representaría más que la culminación del conflicto madre-hijo ${ }^{12}$.

Pero veamos cómo reaparece Dios en el universo de Guerra; cuando Ción, la hija de Guerra, comienza a enfermar, Ángel suplica a Dios la salud de la niña; aparece entonces un Dios metafísico y no interior que es dador de vida, un ser lejano que poco a poco se irá interiorizando, se irá humanizando hasta convertirse en el «padre de la vida» tolstoiano ${ }^{13}$.

Lo cierto es que la desilusión política de Ángel y las sucesivas muertes de su madre y de su hija lo lanzan hacia la crisis, ya que, perdida su causa política y los objetos de su rebelión filial y de su amor paternal, se encuentra a sí mismo desolado, angustiado, viviendo en el vacío. Las necesidades de afirmar su propia personalidad se verán subordinadas al empeño por parte de Guerra de dar un sentido espiritual a su existencia ${ }^{14}$.

Así pues creemos que el tratamiento del tema de la muerte de la hija da entrada a dos elementos en el texto; en primer lugar al tema de la paternidad y en segundo lugar al nacimiento de la fe y a la aparición del dolor.

En cuanto al primero no solo remite al tratamiento del tema por parte de Clarín, sino que será éste un factor esencial en muchos textos novelescos del

11 Utilizamos la edición de Resurrección publicada por Juventud en el año 1984. Nos referimos a la pág. 435.

12 Ver John H. SinNigen «The problem of the individual and social redemption in Angel Guerra», Anales galdosianos, Año XII, 1977, págs. 131 y 132.

13 Del concepto que posee de Dios nos habla Tolstol en En qué consiste mi religión. Moscú 1911 ; para TOLSTOI «Dios es la vida»; sobre el tema ver PORTNOFF, op. cit., págs. 179 y ss.

14 Ver KATHLEen M. SAYERS, "El sentido de la tragedia en Ángel Guerra», Anales Galdosianos, Año V, 1970, pág. 83. 
momento. En el caso de Ángel Guerra, de un matrimonio desgraciado nacerá una hija que morirá y posibilitará un cambio de comportamiento en su padre: ese amor paternal se transformará en amor a la humanidad convirtiéndose así el deseo de continuidad en el hijo en la eternidad del amor universal. Dios o el principio del Bien posee continuidad a pesar de la existencia del Mal, la ruptura o la esterilidad ${ }^{15}$. La orfandad de la carne podrá ser superada por la continuidad del espíritu ${ }^{16}$.

Es curioso, por otra parte, el hecho de que las dos grandes corrientes de la novela espiritualista de finales del XIX, la ruso-hispánica y la francesa, con diferentes y muy marcados rasgos novelísticos, coincidan en el tema de la paternidad; según J. Oleza ambas corrientes se plantean el tema «en términos de realización vital y redención moral ${ }^{17}$.» Así en ellas el hijo revela al padre su destino y da a su vida una nueva dirección; es la relación padre-hija el hecho causante de la aparición de Dios y consecuentemente el hecho que motiva el posterior camino interno de conversión y de transformación del protagonista. El conflicto se produce cuando el individuo cobra conciencia de su situación e inicia una búsqueda de la solución que dé sentido a su existencia. En ese cambio aparecerán las situaciones climáticas.

En cuanto al segundo tema desencadenado por la muerte de la hija, que podríamos fijar como el nacimiento de la fe y el acercamiento al dolor y al sufrimiento humanos como camino, observamos la cercanía entre el pensamiento de Galdós y la ideología de Tolstoi, si bien requeriría este aspecto un mayor detenimiento ${ }^{18}$.

15 J. OLEZA en «De novelas y paternidades: Clarín, Bourget, Rod y Marguerite», Homenaje al profesor Antonio Vilanova, Facultad de Filología, Universidad de Barcelona, 1989, págs. 473485, analiza el tema de la paternidad en las obras de Clarín y de otros autores espiritualistas; me parece relevante la cita de $L a$ noche mala del diablo, obra en la que la ausencia del hijo se relaciona con la visión de Dios como principio genesíaco del Bien, frente al Diablo como principio de la esterilidad y del mal, pág. 474.

16 En «Su único hijo versus La Regenta: una clave espiritualista», Realismo y naturalismo en España en al $2^{a}$ mitad del siglo XIX, Barcelona, Anthropos, 1988, págs. 412-444, OLEZA alude al tema de la orfandad como símbolo del desamparo cósmico de los hombres; «como en el Evangelio, el Hijo revela al Padre y en esta revelación el mundo cobra sentido y redención»; pág. 422.

17 J. Oleza, en el prólogo a Su único hijo de L. Alas Clarín, op. cit., pág. 127.

18 Menéndez y Pelayo ya ve en ese cambio que se produce en Galdós cuando escribe Ángel Guerra, ciertas huellas religiosas de Tolstol; ver Discursos, Madrid, 1897, págs. 33-96. PORTNOFF sin embargo y creemos que un tanto superficialmente afirma: «no vemos influencia de estos autores (se refiere a Tolstoi y Dostoievski) en Ángel Guerra. Nos parece que esta novela tiene más bien huellas de Don Quijote», op. cit., pág. 191. No habría que olvidar, como afirma FranClSCo Ayala, que Galdós aprendió a novelar leyendo El Quijote, en La novela: Galdós y Unamuno, Seix Barral, Barcelona, 1974, pág. 72. 
No podemos olvidar por otra parte que en Ángel Guerra se produce paralelamente a la aparición de la fe, el comienzo del influjo de Leré; sin embargo el amor de Leré no produce una instantánea conversión de Ángel ya que este se resiste en parte a sus consejos ${ }^{19}$.

Esa mencionada aparición de Dios significa en Ángel Guerra el comienzo de un camino o viaje interno que se desarrollará espacialmente en Toledo en una simbología en la que Madrid, símbolo del mundo político se opone a Toledo, símbolo del mundo espiritual ${ }^{20}$. La compatibilidad entre Toledo y su nueva orientación facilitará la actitud de observación y autoanálisis en Guerra.

El camino a seguir se presenta en varias etapas; en un principio aparece la «fe provisional» de Guerra, el descubrimiento del espíritu y la emoción estética:

«Admitía ya cierta fe provisional, una especie de veremos, un por si acaso que era ya suficiente estímulo para que viese con respeto cosas que antes le harían reír. Por de pronto reconocía que en el mundo de nuestras ideas hay zonas desconocidas ... Ignoraba si aquel prurito suyo de probar las dulzuras de la piedad obedecía a un fenómeno de emoción estética o de emoción religiosa ...» (Ángel Guerra, op. cit., pág. 243).

Sin duda ello responde en Galdós en cierto modo a la etapa de interiorización de la realidad como consecuencia de una crisis ideológica. Así crea unos personajes, y Ángel Guerra es una muestra de ello, cuyo mundo interior desborda las relaciones sociales ${ }^{21}$. Ello supone una superación del naturalismo que tendrá en el autor consecuencias en la concepción de la novela.

Una segunda etapa está representada por el descubrimiento del amor por Leré: fe y amor se desarrollarán paralelamente.

La tercera etapa sería la culminación de ese primer viaje y se produce con el entendimiento, por parte de Guerra, de la conformidad como supremo ideal del hombre. Se relaciona ello con la valoración que Galdós hace del individuo

19 Sobre el tema habla JENNIFER LOWE en «Structural and linguistic presentation in Galdo's Angel Guerra", Anales galdosianos Año X, 1975, pág. 47.

20 Casalduero, en op. cit., pág. 89, explica que lo que Galdós busca es un ambiente adecuado a la acción y encuentra esa atmósfera propicia en Toledo.

21 Ver J. Oleza, La novela del siglo XIX, op. cit., pág. 112. 
como fuerza frente a la sociedad, así crea un nuevo héroe que pretende seguir el camino que le dicta su conciencia ${ }^{22}$.

La primera fase del proceso termina con la caída en el pecado ya que Ángel regresa a Dulcenombre.

\section{El deseo de pragmatismo o el segundo camino de perfección}

El punto de partida es el deseo y firme propósito de imitar a Leré, dada la imagen idealizada que posee de ella; así Guerra decide crear una fundación dedicada a la vida activa y contemplativa. La mezcla de lo activo con lo contemplativo procedería de la religiosidad moderna y tal vez de la figura de doña Ernestina Manuel de Villena ${ }^{23}$, pero también es fruto del amor de Ángel Guerra hacia el pasado religioso y hacia las enseñanzas del Nuevo Testamento, si bien no hay que olvidar que la fundación también recuerda las antiguas pretensiones anarquistas e idealistas de Guerra.

Sus planes son expuestos con toda claridad; en primer lugar, recupera su creencia y decide fundar una orden; en segundo lugar, rechaza el mundo y la política; en tercer lugar acepta a la Iglesia aunque con reservas, alejándose así por un lado de las ideas de Tolstoi al respecto y por otro de su Nazarín; la idea global se basaría en que el mal y el bien son igualmente positivos.

«Desechada la creencia, en él antigua, de que sólo el mal es positivo y de que el bien no es más que una pausa o descenso del mal, estableció y dogmatizó la doctrina lereana de que el mal y el bien son igualmente positivos con la diferencia de que el mal se determina en uno mismo, y el bien en los demás, es decir, que la concreción del mal es sufrirlo, y la del bien hacerlo» (Ángel Guerra, op. cit., pág. 340).

Sin duda el planteamiento responde al descubrimiento del hecho de que la realidad es un misterio y de que la materia entra en conflicto necesariamente

22 J. OlezA, La novela del siglo XIX, op. cit., pág. 120, señala que este nuevo héroe se refiere ya a novelas posteriores como Nazarín o Halma; no obstante creemos que en Ángel Guerra se está ensayando la nueva concepción del héroe posterior.

23 Casalduero en op. cit., pág. 28, afirma que Doña Ernestina Manuel de Villena interesó mucho a GALDOS; de familia aristocrática, agraciada y jovial, a los 20 años decidió dedicarse a los menesterosos; en ella vio GALDós el tipo moderno de religiosidad. 
con el espíritu; Galdós entonces comienza a sentir con fuerza el valor religioso del espíritu y se pregunta cómo vivir desde lo ético; así, aunque no niega los ideales naturalistas, los quiere superar ${ }^{24}$. A esa misma pregunta Tolstoi había respondido con el pragmatismo, con la identificación de lo útil con lo verdadero, con la acción sobre la contemplación; pero el elemento que sustenta el criterio de Tolstoi es la fe: el hombre se siente aplastado por lo infinito y nuestra elección viene determinada por la utilidad, lo que propone una clara concepción del sentido de la vida ${ }^{25}$.

En suma ante preguntas como «¿qué hacer?», «¿cómo vivir?», el hombre podrá optar por dos modelos como ya indicaba Clarín; será un revolucionario o un santo; Ángel Guerra acaba de optar por lo segundo y así nace el «hombre nuevo" y comienza su camino de perfección:

«Vio en su existencia un destino grande, aunque subordinado a otro destino mayor y comparándose con el hombre de antes no pudo menos de despreciar todo lo que fue y de enorgullecerse por lo que era, vanagloria legítima sin duda, no incompatible con el propósito de anularse socialmente ...» (Ángel Guerra, op. cit., pág. 340).

En ese «hombre nuevo» que es ahora Ângel Guerra se producen algunos cambios externos, como la percepción de la importancia de la vida religiosa, la admiración del esplendor de la iglesia, la relevancia de la imagen del crucificado o la devoción a la Virgen; y algunos otros internos, como el rechazo de la tentación o el triunfo de Ángel Guerra ante su mayor enemigo: él mismo; no obstante habría que hacer observar la aparición de cierto orgullo no compatible con la caridad ${ }^{26}$.

24 J. OlezA explica en La novela del siglo XIX, op. cit., pág. 114, que esa pregunta del cómo vivir surge además del enfrentamiento individuo/sociedad, de la contradicción de ambos, de la coacción que la sociedad impone al individuo; la respuesta estaria en el difícil y casi imposible equilibrio.

25 Del tema nos habla Charles Badouin, en Tolstoi educador, Instituto Internacional de Educación, Ginebra, s.a.

26 JENNIFER LOWE en op. cit., pág. 50, señala que habría que hacer algunas reservas a ese triunfo; aludiendo a otro capitulo del libro, MONROE Z. HAFTER en op. cit., pág. 46, afirma: «Clearly Angel's pride and ambition as well as the thinness of his religions faith at this stage are obstacles to his identification with the crude people gathered arround the fire»; tambien RICARDO GULLON describe cómo ese viejo Ángel «dominador y violentom, reaparece en ciertos momentos, en Galdos, novelista moderno, Madrid, 1960. 
La culminación del proceso, en el transcurso del cual aparece un Dios justiciero que someterá a prueba a Ángel, se produce cuando se imagina como sacerdote. La aparición sucede varias veces pero el clímax se alcanza cuando al abandonar la catedral Ángel sigue a la figura y de pronto ambos se preguntan: «¿Dómine, quo vadis?». Estas fueron las palabras de Pedro a Jesús. Así está anticipando el narrador el martirio de Ángel ${ }^{27}$.

Pero el personaje reacciona en su individualidad, no la niega y en ella encuentra su fuerza. El héroe espiritualista que se sustenta en su voluntad de perfección no puede renunciar a su individualidad porque a su vez ésta está sustentada en su soledad. Sólo la perfección del individuo es posible. Se está fraguando en Galdós la crisis interior, una crisis estética que, según Casalduero, es paralela a una crisis moral y que inevitablemente nos hace pensar en la crisis estética y ética de Clarín.

El nuevo héroe que está creando Galdós aspira a la revolución del individuo y no a la revolución social; la actitud individualista de Ángel Guerra, que era un rebelde contra la sociedad y que fracasa, permanece en una filosofía individualista; todo ello dará lugar al humanitarismo utópico de Galdós o a la acción individual como única forma de luchar contra la injusticia; pero ello se verá más tarde, a partir de $1898^{28}$.

De esa individualidad como elemento de identificación personal surge en Guerra el rechazo del amor humano a Leré y la aceptación de que Leré ha sido el móvil de la transformación.

Esta segunda fase termina con la caída de Ángel en la tentación, al sentirse atraído por Leré, aunque no en el pecado; no obstante existe en él una conciencia de pecado.

\section{La permanencia en la contradicción, el regreso a la realidad y la perduración del amor}

El punto de partida en esta tercera fase del proceso es la superación del pecado, lo que lleva a Ángel a plantear los fines eminentemente prácticos de su fundación; sin embargo subsiste en Ángel el problema de la razón y la fe:

27 De ello nos habla MONROE Z. HAFTER en op. cit., pág. 43; el autor afirma: «Traditionally, every meeting with a Doppelgänger augurs death, but Guerra's vision of him self as a priest underscores the Christian lesson to be derived form his murder.»

28 OLEZA, en La novela del siglo XIX, op. cit., págs. 136-138, habla del tema y afirma que GaLDós no se hace revolucionario porque entiende que la salvación sólo se hace posible a nivel individual. 
«iDichosos los que no llevan aquí el terrible espejo de la razón, desvanecedor de los engaños de la fantasía, porque elios están mejor preparados para la fe!. Yo con mi razón firme y bien educada, siéntome sujeto cuando quiero lanzarme a creer y mi propio sentido desvanece la dorada ilusión del milagro» (Ángel Guerra, op. cit., pág. 572).

No podemos olvidar a propósito de esta cita, el hecho de esa permanente inquietud de Galdós, religiosa y estética y no sólo política, que le lleva a una síntesis obligada al final de su vida ${ }^{29}$.

La exposición de los principios de la doctrina de Ángel, basada en el cristianismo, da pie para que el personaje explique el significado de términos como Justicia, Redención y Penitencia; remiten estos principios a la ideología que emana de los mandamientos de Tolstoi; éste se basa en San Mateo y en San Lucas y propone como elemento central de su doctrina la no resistencia ${ }^{30}$. Afirma Ángel:

«Mis ideas no son nuevas; interpreto y explico la doctrina de Cristo ... Todo se reduce a muy poco, y mi explicación cabría, como vulgarmente se dice, en un librillo de papel de fumar. Anular la propia personalidad y no ver más que la del prójimo; no matar, no castigar, no defenderse; no alegar ningún derecho; hacer el bien a los demás y guardar el mal para sí; sucumbir siempre ante la ingratitud y la violencia. ¿Ya ves cuán sencillo! ... La perversidad concluirá por rendirse.» (Ángel Guerra, op. cit., pág. 627).

El Galdós de ese momento es un buscador de la verdad, un hombre inmerso en el espiritualismo que intenta encontrar verdades absolutas, que afirma que el valor de los actos reside en la intención y que el dolor es necesario para el perfeccionamiento; no es extraño entonces el hecho de que Galdós crea que haya que inventar la justicia si ésta no existe ya que el hombre sí que posee el sentido de la misma.

29 De ello habla CaSAlduero, op. cit., pág. 29.

30 VERA COLIN en «A note in Tolstoi and Galdós», Anales galdosianos, Año II, 1967, afirma en la pág. 193 que la doctrina de Tolstol está expuesta en Crítica de la teología dogmática. Breve exposición del evangelio y En qué consiste mi religión, textos todos ellos también citados por $\mathrm{G}$. PORTNOFF en La literatura rusa en España, op. cit. 
Así pues todo pensamiento y acción debería tamizarse por «la muerte del egoísmo»: el sentido del mal y del bien, el dolor, la abnegación, la redención ${ }^{31}$.

Pero observemos brevemente las bases ideológicas de esa doctrina que ha expuesto Guerra; el problema se centraría en la dicotomía Realidad-Idea; sabemos que en la época naturalista Galdós deseaba que España dejase de soñar y entrase en la realidad; ese negativismo de la imaginación se convierte ahora en algo positivo; entre las consecuencias de esa primacía, el deseo de valores absolutos frente al relativismo y el paralelismo que se establece entre el conflicto Realidad-Imaginación y Sociedad-Individuo.

El relativismo idealista de Sanz del Río, procedente de Kant y del idealismo alemán, y el krausismo, basado en el «racionalismo armónico» y en el panteísmo, están tras ese deseo de síntesis entre Realidad e Idea, entre Individuo y Sociedad.

Y así es como Ángel Guerra llega a la ideología del amor; habiendo partido del rechazo a la degradación social pretende implantar los ideales humanitarios en la sociedad mediante la caridad y el amor; son los mismo ideales que el príncipe Nejludov propone al final de Resurrección; para éste, el único fin que posee la vida es el elegir los mandamientos con el fin de conseguir el establecimiento del reino de Dios sobre la tierra; el amor es el sustento de las relaciones humanas junto con la libertad y el mal procedería de la creencia por parte de los hombres de que se pueden relacionar sin amor. En el pensamiento de Tolstoi la libertad, la no violencia, el orden moral que emanaba de la anarquía externa, la superioridad de la vida sobre la inteligencia, la primacía del conocimiento de lo concreto sobre lo abstracto, se hermanaban con la ley del amor.

Pero Ángel Guerra, al igual que Don Quijote regresa a la realidad antes de la muerte; se da cuenta de la verdadera función de Leré en su vida y se arrepiente de los sueños de grandeza en cuanto a la fundación de la orden.

Algunos han entendido su fracaso como una muestra de la incapacidad de Guerra para resolver sus problemas internos ya que nunca ha comprendido el conflicto entre su deseo de amor por una parte y su necesidad de independen-

31 Según Oleza en «Su único hijo versus La Regenta», op. cit., págs. 433-434, en aquella atmósfera de religiosidad la solución de los conflictos radicaba en la desaparición del egósmo como en Tolstol; remite a varias obras de CLARIN como el prólogo ya citado a Resurrección, "Amo y criado: último cuento de Tolstoi", en A. RAMOS GASCÓN, Clarín, obra olvidada, Madrid, Júcar, 1973; también Clarín reivindica el dolor cristiano en el Zola de La Terre, en Ensayos y Revistas "Zola: La Terre», Madrid, Fernández Lasanta, 1892; por último OleZA afirma que una exposición básica sobre el dolor redentor la expone CLARÍn en su obra Teresa. 
cia por otra; así, trataría de resolver sus conflictos creando una utopía colectiva ${ }^{32}$.

Por otra parte este fracaso final remitiría al tema de la resistencia al mal en Galdós; todo parece indicar que Galdós había leído muchas de las obras de Tolstoi antes de ser traducidas al español y que se había fijado especialmente en la doctrina de la resistencia al mal; pero también todo parece indicar que llegó a la conclusión de la imposibilidad de su aplicación: el reino de los cielos es imposible en la tierra ${ }^{33}$.

Sin embargo al final, antes de morir, exclama Guerra:

"Gracias a tí (dirigiéndome a Leré) el que vivió en la ceguedad muere creyente» (Ángel Guerra, op. cit., pág. 640).

La muerte de Ángel Guerra no obstante se presenta con cierta ambigüedad ya que no recibe los Santos Óleos; a pesar de ello la ciega Lucía lo ve ascender al cielo. No sería pues su muerte la de un mártir en la que todo el sentido de la tragedia personal desapareciese en su victoria moral; es la muerte de un ser que sufre hasta el final el conflicto interior que en ocasiones parece no haberse resuelto $^{34}$. En suma en Ángel Guerra la expiación de la culpa posibilita la redención del héroe y esa redención suele tener lugar gracias a «la apoteosis del amor».

Ángel Guerra sería un ejemplo de ese grado máximo de despliegue del esquema espiritualista ya que su amor es un amor a la humanidad; así el héroe redimido aspira a proyectar sobre la humanidad sus propios valores convirtiéndose en un santo civil ${ }^{35}$.

Así, al final de la obra, el amor perdura como resto de los sueños de Ángel:

«... el amor, si iniciado como sentimiento exclusivo y personal, extendido luego a toda la Humanidad ... Me basta con esto» (Ángel Guerra, op. cit., pág. 640).

32 Así opina John M. SinNigen, en op. cit., págs. 136-137.

33 Vera Colin en op. cit., pág. 157, explica además que Galdós llegó a crear caracteres tolstoianos e incluso les hizo actuar a la manera del autor ruso, pero la doctrina de resistencia al mal fracasó.

34 Ver Kathleen M. Sayers, op. cit, pág. 82.

35 Según Oleza en el Prólogo a Su único hijo, op. cit., pág. 130, los «santos civiles» abundan en las novelas rusas y españolas; el modelo por excelencia fue el Nejludov de Resurección. 
Se ha culminado un proceso de aprendizaje hacia la santidad en el que un revolucionario se ha convertido en un santo; pero en ese proceso ha manifestado su carácter trágico porque durante el mismo se han manifestado las tremendas contradicciones internas del héroe. Nos recuerda esto el comentario que hace el narrador de Resurrección respecto al príncipe Nejludov en cuanto al hecho de que los caracteres no son de una pieza ya que los hombres llevan en ellos los gérmenes de las facultades humanas ${ }^{36}$. No es extraño pues que Clarín se sintiera impresionado por la puesta en práctica de la teoría de los caracteres opuestos, por la contradicción dentro de un mismo personaje en las novelas espiritualistas rusas $^{37}$.

Se ha hablado por otra parte de la estructura circular de la obra ya que comienza con una situación que se repite al final: la de Ángel herido en el lecho ${ }^{38}$; pero como elemento unificador de la obra, la figura de Ángel, quien como un héroe clásico, se niega a aceptar sus limitaciones; de ahí nace el aspecto trágico de la obra, de la lucha interna del protagonista, el cual evidencia una realidad nacional en la que la intrahistoria de España aparece en lo que ésta tiene de querer vivir lo que no se es ${ }^{39}$.

Así lo que vemos reflejado en el texto en un personaje que parte de la historia hacia una realidad trascendente en una dialéctica de lucha interna con su propia conciencia. Lógicamente aparece el sufrimiento, que algunos han interpretado como ocasionado por la inhabilidad de Guerra para distinguir el fondo sensual de su apego por Leré. Guerra solo llegaría al conocimiento de sí mismo mediante el amor que había nacido de la necesidad de sentirse aceptado y de proyectar su ideal fuera de $\mathrm{si}^{40}$. El sufrimiento de Guerra nacería pues del conflicto entre el amor espiritual y pasional y así el núcleo temático en la tragedia de Ángel Guerra se convierte en la renuncia: Guerra se ve obligado a renunciar

36 Resurrección, op. cit., pág. 228.

37 De ello nos habla en «Más sobre Realidad», incluido en Galdós, Madrid, Renacimiento, 1912.

38 JeNNifER Lowe en op. cit., pág. 46, afirma: «The title of chapter I is Desengaño, that of the last, Final. It is significant that they are virtually interchangeable.»

39 RUIz RAMON en Tres personajes galdosianos, op. cit., pág. 100, afirma de Ángel Guerra que «ansía ascender $a$ un más alto plano humano.»

$40 \mathrm{~K}$. M. SAYERS en op. cit., pág. 83, añade a esto el hecho de que la dominación matriarcal en la familia Guerra ha contribuido mucho a la formación de un desbalance psíquico en el personaje. SAYERS intenta explicar la afinidad entre Ángel y Leré mediante el esquema de Jung y remite a JOAN CARRIE, $A B C$ of Jung's Psychology, London, 1928, págs. 11-27: según Jung el subconsciente del hombre es femenino y el de la mujer masculino; cuando en un carácter predomina el subconsciente se producen las primacías; la mujer así admitiría una serie de opiniones de cualquier autoridad masculina y su carácter estaría dominado por la inflexibilidad; esto sería lo que sucede a Leré. 
a lo pasional porque en él también y con la misma fuerza surge lo espiritual; creemos que no se podría hablar en caso alguno de sublimación de su pasión amorosa y de derivación hacia el fervor místico; por otra parte el conflicto interno entre Realidad y Espíritu vincula la novela con la novela espiritualista de fines de siglo.

Así en Ángel Guerra están presentes el irracionalismo, el rechazo del positivismo, la proclamación de la conciencia como primer mecanismo de conocimiento con la consiguiente primacía de la voluntad y la intuición, el mundo interior como esencia de lo real, la exaltación de la libertad y la espontaneidad y la imposición de una moral de valores absolutos, una moral del sacrificio y de la abnegación, una moral en definitiva del santo o del héroe ${ }^{41}$. Por otra parte, no obstante, fue Tolstoi el autor que a partir de 1888 influyó más en la literatura española y europea sobre todo por la difusión que adquiere el cristianismo humanitario libre de dogmas ${ }^{42}$.

Ángel Guerra, novela exponente como ya hemos indicado de «la realidad interiorizada», presenta el problema de la imposible armonía del realismo; representa así el inicio de un proceso en el que el Ideal va englobando a la Materia hasta que ésta llega a desaparecer y es la expresión por otro lado de una lucha del individuo contra la sociedad en la que éste no la vence pero se vence a sí mismo; por ello no es la culminación de un proceso de repercusiones sociales sino individuales. Pero tampoco podríamos olvidar que es también la manifestación de una sincera inquietud y de un deseo de profundización en el sentimiento religioso de un hombre y de un pueblo. Lo que tiene de plurisignificativo el texto literario se hace así presente de nuevo en Ángel Guerra: una historia

41 J. Oleza en el prólogo a Su único hijo, op. cit., pág. 123, afirma: «El movimiento espiritualista es esencialmente filosófico y abarca a diversas corrientes de pensamiento heredadas de MAINE DE BIRAN (1766-1824) y que imponen un protagonismo en el panorama filosófico francés y alemán de fin de siglo.» Enumera luego las características del movimiento y añade: «Pero el espiritualismo no fue tan solo un fenómeno filośfico, a finales de siglo es toda una oleada cultural que conmueve a los intelectuales y artistas más representativos del régimen liberal»; así, en Francia la «trinidad laica» formada por RENAN, TAINE y ZOLA comienza a ser destronada y todo el mundo cultural se siente atraído por la nueva corriente.

42 PORTNOFF quien, como hemos afirmado ya, no ve influencia de Tolstol en Ángel Guerra, afirma que Galdós se parece a TOLSTOI en la capacidad común de crear lo más trágico y lo más noble en la gente sencilla; en la lucha contra los convencionalismos, en la aspiración al bien y, en suma, en creer en la posibilidad de la regeneración humana; en op. cit., pág. 129. En otro lugar afirma PORTNOFF, refiriéndose a los dos escritores: "These two great writers accomplished in their respective countries a task at the base of which lies that great idea: deep aspiration to good»... «Both, in different forms, seek God, both pursue hapiness .... en «The beginning of the new idealism in the works of Tolstoi and Galdós», Goeorge PorTnOFF, Romanic Review, volume XXIII, 1932, págs. 33-37; la cita es de la pág. 34. 
de pecado y de conversión, de pasión y de arrepentimiento, de amor y de muerte; una historia en la que la soberbia, el peor de los pecados, es derrotada por el amor universal.

Finalmente, no podría dejar de manifestar mi agradecimiento al Profesor Juan Oleza, a quien debo la orientación y dirección de este trabajo. 